\title{
Distribution of Oxyphinic Elements in Sewage Sludge Fractions Based on Manganese and Nickel
}

\author{
Monika Jakubus ${ }^{1 *}$ \\ 1 Department of Soil Science and Land Protection, Poznan University of Life Sciences, Poland \\ e-mail:monika.jakubus@up.poznan.pl
}

\begin{abstract}
Owing to the chemical composition of sewage sludge (SS), it may be used as an alternative to fertilizers; however, before land application, it must be assessed in terms of its contents of heavy metals considering their potential mobility in the soil. The aim of this study was focused on evaluating the potential mobility of oxyphinic elements $-\mathrm{Mn}$ and $\mathrm{Ni}$ in SS. The samples were collected from 4 different wastewaters treatment plants located in the Wielkopolska province at the same time points in 3 consecutive years. The levels of $\mathrm{Mn}$ and Ni were assessed using the BCR sequential method. The risk assessment code, and individual contamination factor were additionally calculated. The sewage sludge from small WWTPs was characterised by significantly lower amounts of metals in comparison to those originating from the large ones. It was found that both metals were dominant in loosely and relatively loosely bound fractions of all analyzed SS. It was confirmed by high values of risk assessment codes and individual contamination factor. $\mathrm{Mn}$ and Ni belonging to the group of oxyphinic elements showed significant similarities in the distribution of SS fractions. Large and rapidly activated pool of Mn and Ni may be a beneficial and valuable source of nutrients for plants, but certain dangers related to the possible accumulation of these elements in soils could be also considered.
\end{abstract}

Keyword: sewage sludge, sequential method, metals, risk assessment code (RAC), individual contamination factor (ICF)

\section{INTRODUCTION}

After the implementation of EU Directive 1991/271/EEC in 2005 regarding wastewater treatment, the production of sewage sludge (SS) in Poland has significantly increased (CSO 2019). Considering the contemporary challenges in the broadly understood waste management, proper and sustainable management of the increasing mass of sewage sludge is a challenge and a priority, especially that among all the EU countries, Poland generated the highest amount of this waste (Eurostat 2021). Sewage sludge constitutes an environmentally harmful waste that cannot be landfilled (Directive 1999/31/EC). Therefore, the economically most viable and environmentally safe solution to this problem needs to be sought. Presently, the SS management in Poland is mainly based on agricultural application, co-composting for compost production and thermal disposal
(CSO 2019). Taking into account the chemical composition of SS abundant in macro-, micronutrients and organic matter (Górecki et al. 2020; Pöykio et al. 2019; Sanchez et al. 2017), the latter method is least desirable. Thus, land application of SS or the application of composts prepared from SS to agricultural soils is an economically effective alternative to disposal through landfilling or incineration. Land application of sewage sludge is also popular in some European countries, although in order to protect human health this trend led to restricting the use of biosolids based on their quality in relation to the heavy metal limit values (Collivignarelli et al. 2019).

Sewage sludge is recognized as an alternative to traditional organic fertilizers (Jakubus 2020; Sanchez et al. 2017). Additionally, it ensures that the nutrients and organic matter contained in SS are re-incorporated into the circulation in the environment. Moreover, it is well-documented and 
proven that SS or composts prepared on its basis affect various soil properties and serve as a valuable source of nutrients for plants (Alvarenga et al. 2015; Jakubus and Bakinowska 2018; Sharma et al. 2017). Despite its many profits, it is now widely recognized that the use of SS in agriculture as a soil fertilizer raises a potential health impact concern because of its content of heavy metals, which are not biodegradable (Braga et al. 2017; Jakubus 2020; Zhang et al. 2017). The most common sources of heavy metals in SS are domestic and industrial wastewaters, corrosion of sewerage system installations as well as surface runoff from urbanized areas or roads (Duan et al. 2018). According to Regulation of Minister of Environment on sewage sludge (Journal of Laws of 2015) both sewage sludge and the soil where they will be used must comply with the limit values for heavy metals. However, even following the requirements of the cited above Regulation (Journal of Laws of 2015) regarding the maximum sludge dose and the above-mentioned metal threshold values, the unfavorable accumulation of metals in the environment cannot be excluded (Contin et al. 2015). In relation to the above, metals are very often the topic of numerous studies in the context of their presence in SS, as presented in a review by Zhang et al. (2020). Despite the fact that manganese belongs to the group of heavy metals, this element is overlooked in the SS characteristics and according to the author's best knowledge, the information on the subject in literature is scarce. Manganese is the $12^{\text {th }}$ most abundant element in the Earth's crust and the $5^{\text {th }}$ most plentiful metal widely distributed in nature (Röllin and Nogueira 2011). According to the geochemical classification given by Kabata-Pendias and Pendias (1999), manganese, together with nickel, belongs to the group of oxyphilic elements, i.e. those that form oxygen compounds, such as silicates, carbonates, sulfates or phosphates. Manganese is the main element and nickel is an accompanying element in hydrated manganese oxides, which are a type of precipitate formed under aerobic and alkali conditions. The Mn transformations also depend on the redox conditions and $\mathrm{pH}$. Clay minerals, as well as $\mathrm{Fe}$ and $\mathrm{Al}$ hydroxides have a great sorption capacity in relation to manganese. Simultaneously, this metal is weakly bound by organic matter. The geochemical behavior of $\mathrm{Ni}$ is slightly different in comparison to Mn. Nickel is the $24^{\text {th }}$ most abundant element in the Earth's crust and it is the $5^{\text {th }}$ most abundant element regarding weight after iron, oxygen, magnesium and silicon (Genchi et al. 2020). Nickel in the environment is subject to rapid activation, although it is easily bound by $\mathrm{Fe}$ and $\mathrm{Mn}$ hydroxides and organic matter. Apart from exceptional circumstances, ecotoxicity of $\mathrm{Mn}$ and $\mathrm{Ni}$ is rarely reported in practice. Both metals show a very low hazard ranking to the human food chain or terrestrial ecosystems relative to other principal heavy metals. Additionally, both $\mathrm{Mn}$ and Ni are essential micronutrients for plants, although they accumulate poorly in them and reveal an antagonistic relationship during uptake by plants (Kabata - Pendias and Pendias 1999).

Despite the total metal amounts being a basic criterion when assessing the quality and usefulness of sewage sludge for agriculture purposes or reclamation, they do not inform on the potential mobility of elements, especially in the case of sewage sludge soil application (Jakubus 2020; Wojciula et al. 2021). The assessment based on total metal contents may inadvertently overestimate the potential risk (Kim et al. 2015). Hence, more adequate and reliable information is provided by the mobile amounts of metals indicating on a risk of potential exposure for the soil-crophuman transfer. The knowledge of $\mathrm{Mn}$ and $\mathrm{Ni}$ transformation rate and direction, which can take place in soil after SS application is of significant importance. Thus, recognition of the quantitative level of the metals in the loose bonds with sludge matrix is essential and helpful for such a prediction and evaluation. This is due to the fact that theoretically $\mathrm{Mn}$ and $\mathrm{Ni}$, which are quickly activated in the soil after the SS application, become a source of nutrients for plants, but can also lead to their uncontrolled and unfavorable accumulation. The forecast of such changes may be based on the results of sequential analysis. The sequential extraction techniques have been the most widely used methods to study metal distribution in various matrices. Among different methods proposed for the sequential extraction techniques, the BCR method is commonly used for SS because of its simplicity in conjunction with sufficient information regarding metal mobility. The sequential extraction procedure is performed with increasingly aggressive solutions of the reagent. For each step, there is a selected reagent capable of eluting the group of metal compounds with strictly known properties, for example susceptibility of a given element to solubility and mobility. The BCR method defines four main fractions, where the first two (exchangeable and bound to iron and 
manganese oxyhydroxides) are the most important, because metals in these combinations are the most mobile and accessible to plants, while they may also be subject to secondary accumulation in soil colloids (Jakubus 2020; Wojciula et al. 2021; Yang et al. 2017).

The aim of the present study was to evaluate the distribution of $\mathrm{Mn}$ and $\mathrm{Ni}$ as an example of oxyphinic elements within the fractions of SS. Potential variability of quantitative changes in the metals was analyzed in the sewage sludge originating from four WWTPs of different size during 3 consecutive years. It is hypothesized that using sequential method metals in various combinations may be evaluated focusing on readily and potentially readily activated ones. This knowledge gives an opportunity to predict the future behavior of the metals introduced into the soil with SS. The verification of such an assumption was expanded by the application of the risk assessment code (RAC) and individual contamination factor (ICF). The findings will serve as a database to assess the potential impact of SS on the soil environment after its land application.

\section{MATERIAL AND METHODS}

\section{Materials}

The characteristics of SS treatment, collection and its preparation for chemical analyses were presented in detail in an earlier work by Jakubus (2020). Here, general information is given to provide understanding of the context for the research. The sewage sludge samples used in this study were gathered from four wastewater treatment plants (WWTPs) located in the Wielkopolska province. The difference between individual WWTPs is related to the amount of treated municipal wastewater, and thus the generated mass of waste. WWTP 1 and 2 were the largest and served large urban agglomerations. They generated the largest mass of sewage sludge, 17000 and 3500 tons per year, respectively. In turn, WWTP 3 and 4 were smaller, local installations, producing a smaller mass of sewage sludge (730 and $550 \mathrm{t}$ per year for WWTP 3 and WWTP 4, respectively). The SS samples were collected in consecutive years (2017-2019) after the completed process of SS management at the WWTPs. The SS samples were dried at $105^{\circ} \mathrm{C}$ and then were ground to obtain a homogeneous, even structure of a very fine powder. The materials were stored in plastic bags at $4^{\circ} \mathrm{C}$ until chemical analysis.

\section{Methods}

As previously noted, detailed information on the analytical procedures used can be found in an earlier work by Jakubus (2020). Thus, standard and well-known methods were applied to determine the selected parameters of SS, so the Vario Max CNS apparatus was used to determine Ntot and TOC and to assay organic matter, the SS samples were incinerated at $550^{\circ} \mathrm{C}$. Total manganese (Mntot) and nickel (Nitot) contents of sewage sludge were evaluated using the aqua regia procedure (ISO 1995). Distribution of metals in individually separated fractions of SS was analysed with the BCR method (Mossop and Davidson 2003). According to this protocol, the following four fractions are separated: Fr. 1 - exchangeable, water and acid soluble, Fr. 2 - reducible, e.g. bound to iron and manganese oxyhydroxides, Fr. 3 - oxidizable, e.g. bound to organic matter and sulfides, and Fr. 4- residual, non-silicate bound metals. The flame atomic absorption spectrometry (FAAS) with Varian Spectra AA 220 FS apparatus assistance was applied for the assessment of the $\mathrm{Mn}$ and $\mathrm{Ni}$ concentrations in the obtained extracts. The metal amounts in the separated SS fractions allowed determining two independent indices: the risk assessment code (RAC) and individual contamination factor (ICF). The details of the RAC calculations are given by Yang et al. (2017). According to the cited authors, RAC presents a percentage share of $\mathrm{Mn}$ and $\mathrm{Ni}$ found in Fr. 1 in relation to total contents. The obtained values are interpreted on the basis of 5 classes as follows:

RAC $<1 \%$ - no risk (NR, safe to the environment) RAC $1-10 \%$ - low risk (LR, relatively safe to the environment)

RAC $11-30 \%$ - medium risk (MR, relatively dangerous to the environment)

RAC $31-50 \%$ - high risk (HR, dangerous to the environment)

RAC $>50 \%$ - very high risk (VHR, very dangerous to the environment).

The individual contamination factor (ICF) was calculated according to Tytla (2019) and it is the value of the quotient of the sum of the metal 
amounts in fractions from I to III and the amount of metals in fractions IV.

$$
\mathrm{ICF}=\frac{\mathrm{Fr} 1+\mathrm{Fr} .2+\mathrm{Fr} .3}{\mathrm{Fr} .4}
$$

The obtained values are interpreted on the basis of 4 classes, as follows:

ICF $<1$ - low contamination (LC)

$1<$ ICF $<3$ - moderate contamination (MC)

$3<$ ICF $<6$ - considerable contamination (CC)

$\mathrm{ICF}>6-$ very high contamination $(\mathrm{VHC})$

\section{Statistical analysis}

The data presented in the paper are mean amounts of 3 repetitions. Statistical calculations were performed using the STATOBL software working in the Windows environment. Due to the fact that the experiment takes into account three factors: years (A), amounts of metals in the separated fractions (B) and sewage sludge (C), the three-way ANOVA was applied. On the other hand, two-way ANOVA was used for metal total amounts calculation including two factors: years (A) and sewage sludge (B). The Tukey's test at $\alpha=0.05$ level was considered to calculate the least significant differences and to indicate uniform, homogeneous groups (mean contents of metals do not differ significantly) within the factor level. Box-Whiskers plots were constructed to represent the total, amounts of metals. In the boxplot figures, the distribution of data is given by the minimum value, maximum value, median and first and third quartiles are shown for each parameter.

\section{RESULTS AND DISCUSSION}

\section{Physicochemical analysis of sewage sludge}

The detailed information of SS physicochemical characteristic was presented in an earlier work by Jakubus et al. (2021). All SS show an alkali reaction with very comparable $\mathrm{pH}$ values ranging from 7.6 to 8.1. The amounts of $\mathrm{OM}$, TOC and Ntot were very similar for pairs of SS1 and SS2 as well as SS3 and SS4. The mean content of organic matter ranged from $670 \mathrm{~g}^{\cdot \mathrm{kg}^{-1}}$ to $672.2 \mathrm{~g} \cdot \mathrm{kg}^{-1}$ for SS1 and SS2, respectively, and for SS3 and SS4 from $762.2 \mathrm{~g} \cdot \mathrm{kg}^{-1}$ to $767.8 \mathrm{~g} \cdot \mathrm{kg}^{-1}$, respectively. The mean TOC amounts were also higher for SS3 and SS4 (408.9-420.1 $\left.\mathrm{g}^{\mathrm{kg}} \mathrm{kg}^{-1}\right)$ in comparison to SS1 and SS2 (329.6-333.7 g $\left.\mathrm{kg}^{-1}\right)$. Mean total nitrogen level was about $40 \%$ higher in SS3 and SS4 (70.6-73.0 $\left.\mathrm{g} \cdot \mathrm{kg}^{-1}\right)$ in relation to the Ntot amount found in SS1 and SS2 (50.4$\left.51.4 \mathrm{~g} \mathrm{~kg}^{-1}\right)$ (Table 1).

\section{Total amounts of metals}

The total contents of Mn and Ni in the SS vary greatly and generally the nickel contents are smaller than those of manganese (Pöykio et al. 2019). The author's study confirmed this because the total Mn amounts were 2- to 7-fold higher than the total Ni amounts (Table 2). Regardless of the above, the limiting value of $\mathrm{Mn}$ is not considered during the evaluation of the SS chemical composition. The total amounts of $\mathrm{Mn}$ are not subject to quantitative assessment in the $\mathrm{SS}$, which is reflected in the lack of limit levels

Table 1. Mean contents of selected properties of analyzed sewage sludge

\begin{tabular}{|c|c|c|c|c|c|}
\hline \multirow{2}{*}{ Sewage sludge } & OM & TOC & Ntot & \multirow[t]{2}{*}{$\mathrm{C}: \mathrm{N}$} & \multirow[t]{2}{*}{$\mathrm{pH}$} \\
\hline & \multicolumn{3}{|c|}{$\left(g \cdot \mathrm{kg}^{-1}\right)$} & & \\
\hline SS1 & 672.2 & 329.6 & 51.4 & 6.4 & 7.8 \\
\hline SS2 & 670.0 & 333.7 & 50.4 & 6.6 & 7.6 \\
\hline SS3 & 762.2 & 420.1 & 73.0 & 5.8 & 8.1 \\
\hline SS4 & 767.8 & 408.9 & 70.6 & 5.8 & 8.0 \\
\hline
\end{tabular}

Table 2. The mean total metal contents depending on sewage sludge and the years of study $\left(\mathrm{mg} \cdot \mathrm{kg}^{-1}\right)$

\begin{tabular}{|c|c|c|c|c|c|c|c|c|}
\hline \multirow{2}{*}{ Year of study } & \multicolumn{2}{|c|}{ SS1 } & \multicolumn{2}{|c|}{ SS2 } & \multicolumn{2}{|c|}{ SS3 } & \multicolumn{2}{|c|}{ SS4 } \\
\hline & $\mathrm{Mn}$ & $\mathrm{Ni}$ & $\mathrm{Mn}$ & $\mathrm{Ni}$ & $\mathrm{Mn}$ & $\mathrm{Ni}$ & $\mathrm{Mn}$ & $\mathrm{Ni}$ \\
\hline 2017 & 213.75 & 125.07 & 250.75 & 74.85 & 74.82 & 31.30 & 143.44 & 18.62 \\
\hline 2018 & 215.8 & 111.74 & 215.45 & 91.74 & 75.11 & 31.62 & 104.48 & 17.67 \\
\hline \multirow[t]{2}{*}{2019} & 204.04 & 70.95 & 206.37 & 94.09 & 46.38 & 32.78 & 61.95 & 16.09 \\
\hline & \multicolumn{8}{|c|}{$\mathrm{LSD}_{\mathrm{Mn}}$ for $\mathrm{AxB}=2.763$} \\
\hline
\end{tabular}


for this metal both in the Polish (Regulation on sewage sludge, Journal of Laws of 2015) and European regulations (Directive 86/278/EEC). The mean total contents of $\mathrm{Mn}$ in the SS ranged from $65.43 \mathrm{mg} \cdot \mathrm{kg}^{-1}$ (SS3) to $224.19 \mathrm{mg} \cdot \mathrm{kg}^{-1}$ (SS2), with the values being statistically different (Figure 1). The total amounts of Mn found in SS1 and SS2 were 2-3 times higher than those determined for SS3 and SS4. The total content of Mn in the years of the study significantly decreased, which was particularly noticeable in the case of SS3 (lower by 38\% in 2019) and in SS4 (lower by $57 \%$ in 2019) (Table 2). Similarly as in the present study, different amounts of $\mathrm{Mn}$ are also given in the literature (Braga et al. 2017, Zhang et al. 2017, Zhang et al. 2020), being either smaller, larger or in a similar range as those showed in this paper. An opposite situation was observed in the case of nickel, which was identified as a potentially toxic element in the soil subjected to routine monitoring in sewage sludge. The limit values for nickel differ depending on the country and the purposes, for which the sewage sludge is used (Collivignarelli et al. 2019). According to the Regulation of the Minister of the Environment on sewage sludge (Journal of Laws of 2015) and Directive 86/278/EEC, the total content of nickel in SS cannot exceed 300 and $400 \mathrm{mg} \cdot \mathrm{kg}^{-1}$, respectively. Comparing these permissible thresholds with those obtained in the author's research, the tested SS samples met the requirements for their practical use. As in the case of Mn, also the total amounts of Ni determined for SS1 and SS2 were significantly higher than those found for SS3 and SS4 (Figure 1). The total content of Ni in SS1 was 3-to 6-fold higher in comparison to the values found in SS2-SS4. The total amounts of Ni in the years of the study significantly decreased
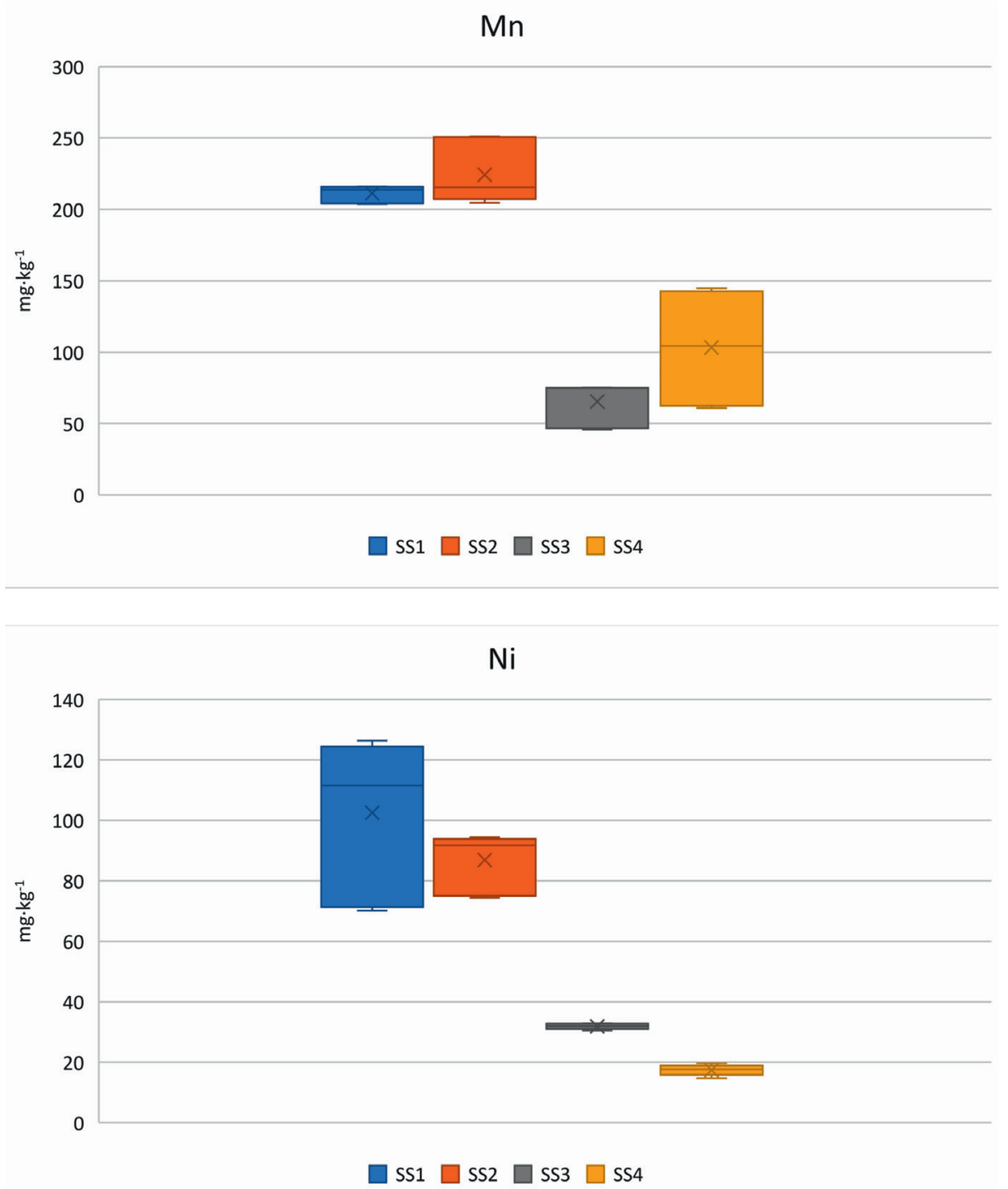

Figure 1. Mn and Ni total contents in analysed sewage sludge (SS) regardless of year of study. 
only in the case of SS1 (by 43\% in 2019). Sanches et al. (2017) also observed a downward trend in the total Ni amounts in SS within the year of the study in WWTPs. SS2 in 2019 showed significantly higher total Ni amounts by $25 \%$ (Table 2). In the literature presenting the total content of $\mathrm{Ni}$ in sewage sludge from different countries, the recorded values are comparable (Braga et al. 2017; Łukowski 2017), higher (Karwowska and Dąbrowska 2017; Yang et al. 2017; Zhang et al. 2020) and lower (Zhang et al. 2017).

\section{Chemical speciation of metals in sewage sludge}

The amounts of Mn in the sequentially separated SS fractions were also the highest in the case of SS1 and SS2 and significantly lower in SS3 and SS4 (Table 3). Regardless of such differences, the quantitative distribution of $\mathrm{Mn}$ in the SS fractions was the same. As can be seen from the data presented in Table 3, the greatest amount of the metal was assayed in Fr. 2 (from $31.27 \mathrm{mg} \cdot \mathrm{kg}^{-1}$ to $111.71 \mathrm{mg} \cdot \mathrm{kg}^{-1}$, on average $72.83 \mathrm{mg} \cdot \mathrm{kg}^{-1}$ ) and in Fr. 1 (from $24.14 \mathrm{mg} \cdot \mathrm{kg}^{-1}$ to $84.05 \mathrm{mg} \cdot \mathrm{kg}^{-1}$, on average $56.73 \mathrm{mg} \cdot \mathrm{kg}^{-1}$ ). The Mn level was significantly lower in organic complexes (from $6.24 \mathrm{mg} \cdot \mathrm{kg}^{-1}$ to $17.68 \mathrm{mg} \cdot \mathrm{kg}^{-1}$, on average $12.5 \mathrm{mg} \cdot \mathrm{kg}^{-1}$ ) and residual forms (from $3.1 \mathrm{mg} \cdot \mathrm{kg}^{-1}$ to $8.33 \mathrm{mg} \cdot \mathrm{kg}^{-1}$, on average $5.70 \mathrm{mg} \cdot \mathrm{kg}^{-1}$ ). This is confirmed by the percentage shares of $\mathrm{Mn}$ in individual fractions presented in Figure 2. The highest percentage of Mn was obtained for Fr. 2 (47.4-50.5\%) and in Fr. 1 (37-39\%). Mn bound with organic matter constituted from 8 to $9.7 \%$, while in the residual fraction it was from 3.2 to $4.8 \%$. The amounts of $\mathrm{Mn}$ in the fractions decreased in the years of the study, which was especially evident in the combinations with organic matter and in residual forms, where in comparison to the amounts found in the samples from 2017 , the levels recorded in 2019 were lower by $47.4 \%$ and 56\%, respectively (Table 4).

A similar quantitative distribution of $\mathrm{Mn}$ in the SS was reported by Pöykio et al. (2019) and Zhang et al. (2017). In turn, Braga et al. (2017) using the Tessier sequential method determined the dominant share of $\mathrm{Mn}$ in organic and exchangeable bonds of SS. Moreover, the cited authors found $\mathrm{Mn}$ as a metal which was most uniformly distributed throughout the separated fractions compared to the other metals. The distribution of $\mathrm{Mn}$ assessed in the present study corresponds to the biogeochemical character of this element, expressed by its strong, preferential sorption on Fe and $\mathrm{Al}$ oxides and hydroxides, and a weaker bond with organic matter. Manganese in the SS may come from various sources, but it mainly originates from the discharge from industrial facilities or leachate from landfills or soils, as reported by Braga et al. (2017). In the case of the studied SS, it is difficult to point to this type of Mn origin in these wastes, although this cannot be excluded. However, a more convincing and reliable source of $\mathrm{Mn}$ in the SS seems to be drinking water and human metabolic transformation, because manganese naturally occurs in many surface water and groundwater sources, particularly under anaerobic or low oxidation conditions, and the above-mentioned sources are most important for drinking water (WHO 2017). Additionally, Braga et al. (2017) underlined its role in methanogenesis during the fermentation of sewage sludge, which is part of one of the SS treatment processes carried out at the wastewater treatment plant within sludge management. The fermentation process is an anaerobic process and under such conditions, $\mathrm{Mn}$ is easily released from various combinations and is reduced to its more soluble form $\mathrm{Mn}^{2+}$. Such transformations may theoretically result in larger amounts of this metal in fraction 1 of SS.

Table 3. Manganese contents in individual fractions of sewage sludge as a mean for the years of the study $\left(\mathrm{mg} \cdot \mathrm{kg}^{-1}\right)$

\begin{tabular}{|c|c|c|c|c|c|}
\hline Fraction & SS1 & SS2 & SS3 & SS4 & Mean for fraction \\
\hline 1 & 81.73 & 84.05 & 24.14 & 37.00 & $56.73 \mathrm{~b}$ \\
\hline 2 & 102.74 & 111.71 & 31.28 & 45.60 & $72.83 \mathrm{a}$ \\
\hline 3 & 16.74 & 17.68 & 6.24 & 9.34 & $12.50 \mathrm{c}$ \\
\hline 4 & 8.33 & 7.15 & 3.10 & 4.23 & $5.70 \mathrm{~d}$ \\
\hline \multicolumn{5}{|c|}{ LSD for BxC = 1.10 } \\
\hline Mean for SS & $52.38 \mathrm{~b}$ & $55.15 \mathrm{a}$ & $16.18 \mathrm{~d}$ & $24.05 \mathrm{c}$ & \\
\hline
\end{tabular}

Note: Homogeneous groups of tested variables are indicated by the same lowercase letters. 

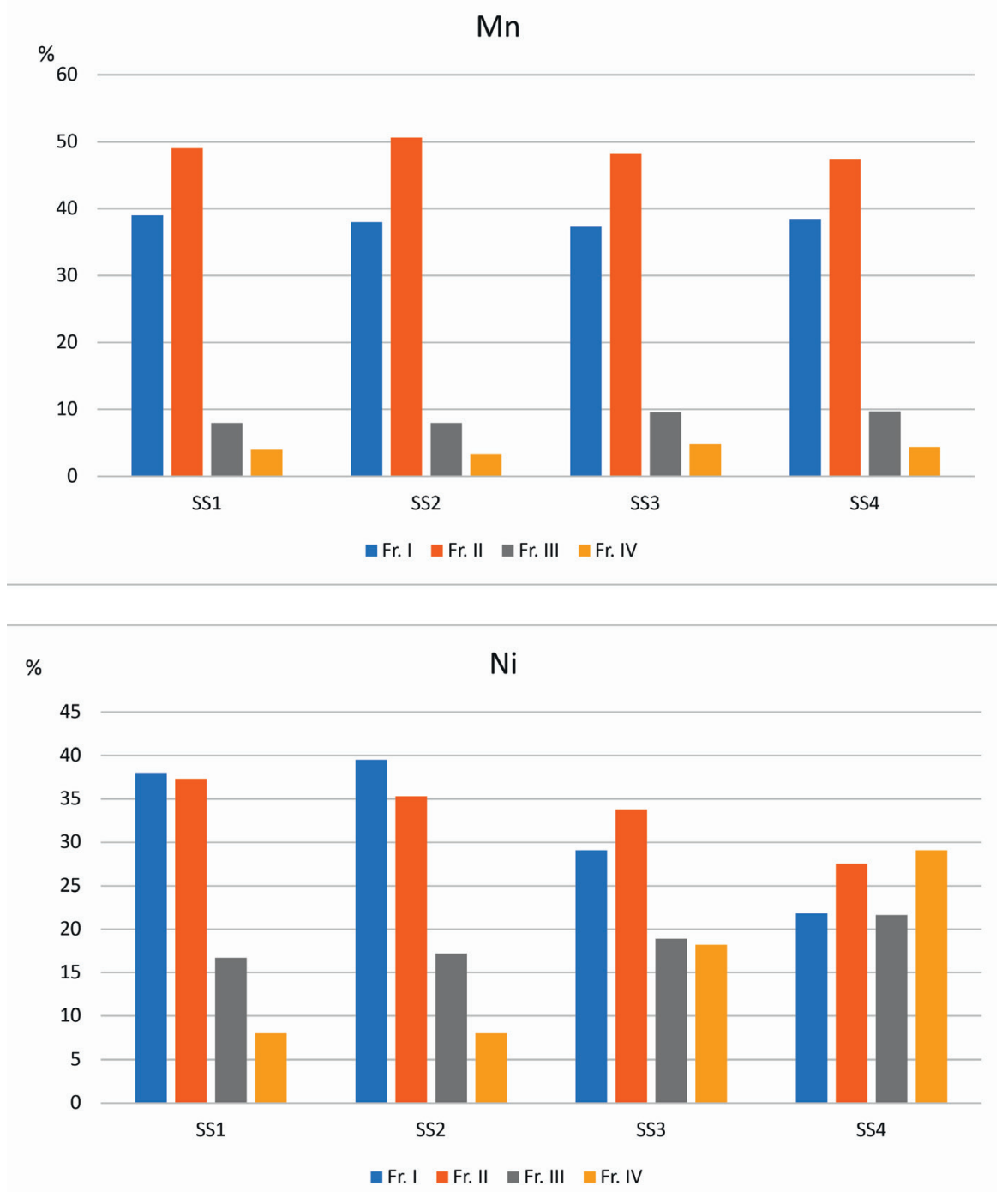

Figure 2. Percentage shares of metals in sequentially separated fractions for sewage sludge (SS1-4)

Regardless of the years of the study, both the dominant share of Mn in Fr. 1 and 2 and a significantly greater amount of this metal in SS1 and SS2 were confirmed by the data presented in Table 4. It is worth emphasizing that the amounts of Mn in SS3 and SS4 in 2019 were lower by 35 and $45 \%$, respectively, compared with the values determined in the samples from 2017. The presence of manganese in drinking water, similarly as iron, may lead to the accumulation of deposits in the distribution system (WHO 2017). This fact could naturally lead to greater content of manganese in SS1 and SS2. The diminished amount of Mn in SS3 and SS4 may be interpreted on the one hand as an improvement in the quality of drinking water. Still it cannot be ruled out that the wastewater treatment process is less efficient for a given treatment plant, as a result of which lesser amounts of metals, including $\mathrm{Mn}$ and $\mathrm{Ni}$, penetrate to the sludge. This means that the process commonly used in WWTPs does not definitely guarantee the removal of heavy metals from influent wastewater and thus heavy metals are transferred to SS only partially. In this context, attention should be paid to the optional use of coagulants by wastewater treatment plants, which not only increases phosphorus removal from the wastewater, but is effective also for trace metals, while promoting better drainage of sewage sludge. As a standard practice, $\mathrm{Fe}$ and $\mathrm{Al}$ compounds (oxides, sulfate, chloride) are used, which at alkaline $\mathrm{pH}$ precipitate as amorphous $\mathrm{Fe}, \mathrm{Al}$ hydrated oxides or oxyhydroxides (Contin et al. 2015) constituting a good matrix for metal sorption. This phenomenon may explain the higher amounts of Mn in Fr. 2. Smaller, local wastewater treatment plants very often limit the amounts of used coagulants because of high operating costs and thus automatically the 
Table 4. Mean manganese contents for fractions and sewage sludge depending on the years of the study $\left(\mathrm{mg} \cdot \mathrm{kg}^{-1}\right)$

\begin{tabular}{|c|c|c|c|c|}
\hline \multirow{2}{*}{ Year of study } & \multicolumn{4}{|c|}{ Fractions } \\
\hline & 1 & 2 & 3 & 4 \\
\hline 2017 & 60.93 & 78.94 & 14.72 & 7.30 \\
\hline 2018 & 59.05 & 71.27 & 13.46 & 6.62 \\
\hline 2019 & 50.21 & 68.29 & 9.32 & 3.19 \\
\hline \multirow[t]{3}{*}{ Mean for the years } & 56.70 & 72.80 & 12.50 & 5.70 \\
\hline & \multicolumn{4}{|c|}{ Sewage sludge } \\
\hline & SS1 & SS2 & SS3 & SS4 \\
\hline 2017 & 50.13 & 59.48 & 19.11 & 33.16 \\
\hline 2018 & 55.23 & 54.27 & 17.11 & 23.78 \\
\hline 2019 & 51.80 & 51.70 & 12.34 & 15.18 \\
\hline \multirow[t]{2}{*}{ Mean for the years } & 52.38 & 55.15 & 16.19 & 24.04 \\
\hline & \multicolumn{4}{|c|}{ LSD $=0.864$} \\
\hline
\end{tabular}

potential sorption matrix for metals is smaller. In the presented study, the Mn levels in Fr. 2 in SS3 and SS4 were 2- to 4-fold lower in comparison to the amounts assessed in SS1 and SS2 (Table 3).

As it was previously shown for total $\mathrm{Ni}$ levels, also the amounts of this metal in sequentially separated fractions were the highest for SS1 (on average $25.12 \mathrm{mg} \cdot \mathrm{kg}^{-1}$ ) and SS2 $\left(20.85 \mathrm{mg} \cdot \mathrm{kg}^{-1}\right)$, while they were significantly lower for SS3 (on average $8.59 \mathrm{mg} \cdot \mathrm{kg}^{-1}$ ) and SS4 (on average $5.03 \mathrm{mg} \cdot \mathrm{kg}^{-1}$ ) (Table 5). Regardless of the above, the quantitative distribution of $\mathrm{Ni}$ in the $\mathrm{SS}$ fractions was similar (Table 5, Figure 2). The most Ni in SS1, SS2 and SS3 was found in Fr. 1 (from $10.03 \mathrm{mg} \cdot \mathrm{kg}^{-1}$ to $38.21 \mathrm{mg} \cdot \mathrm{kg}^{-1}$ ) and Fr. 2 (from $11.6 \mathrm{mg} \cdot \mathrm{kg}^{-1}$ to $37.37 \mathrm{mg} \cdot \mathrm{kg}^{-1}$ ), which was reflected in the percentage share from 29.2 to $39.5 \%$ in Fr. 1 and from 33.8 to $372 \%$ in Fr. 2 (Figure 2). A slightly different distribution of the metal was found for SS4, where the highest content of $\mathrm{Ni}$ was recorded in Fr. $4\left(6.57 \mathrm{mg} \cdot \mathrm{kg}^{-1}\right)$ and in Fr. $2\left(5.26 \mathrm{mg} \cdot \mathrm{kg}^{-1}\right)$, constituting 34.5 and $27.5 \%$ of the total content, respectively (Table 5 , Figure 2). The levels of this metal $\left(4.18 \mathrm{mg} \cdot \mathrm{kg}^{-1}\right)$ as well as its percentage share in Fr. 1 and 2 of
SS4 were the same (21.6\%) (Table 5, Figure 2). A similar Ni distribution in municipal sewage sludge fractions was indicated by Pöykio et al. (2019). Zhang et al. (2017) determined almost equal shares of $\mathrm{Ni}$ in the separated SS fractions, with slightly greater $\mathrm{Ni}$ amounts in Fr. 1. The higher Ni contents in exchangeable and residual bonds were indicated by Yang et al. (2017) and Tytla (2019). Besides $\mathrm{Zn}$ and $\mathrm{Cd}$, Ni is recognized as an element of relatively high mobility (Kim et al. 2015), and especially it is connected with salts of strong acids (chloride, nitrate and sulfate) and organic salts being readily water soluble (Genchi et al. 2020). The data showed in the present study, also confirmed by other authors, are consistent with the geochemistry of Ni behavior, discussed earlier. Nickel is also subject to easy sorption on oxides and hydroxides of $\mathrm{Mn}$ and $\mathrm{Fe}$, which can be favored by the use of coagulants in wastewater treatment, as it was already explained in the case of manganese. Depending on the application of coagulants, the potential sorption capacity in relation to nickel may vary and this will be reflected in a greater or lesser amount of $\mathrm{Ni}$ in reducible connections. The correctness of such an interpretation is

Table 5. Nickel contents in individual fractions of sewage sludge as means for the years of the study $\left(\mathrm{mg} \cdot \mathrm{kg}^{-1}\right)$

\begin{tabular}{|c|c|c|c|c|c|}
\hline Fraction & SS1 & SS2 & SS3 & SS4 & Mean for fraction \\
\hline 1 & 38.21 & 32.95 & 10.03 & 4.18 & $21.34 \mathrm{a}$ \\
\hline 2 & 37.37 & 29.40 & 11.60 & 5.26 & $20.91 \mathrm{~b}$ \\
\hline 3 & 16.83 & 14.40 & 6.50 & 4.18 & $10.47 \mathrm{c}$ \\
\hline 4 & 8.06 & 6.65 & 6.24 & 6.57 & $6.87 \mathrm{~d}$ \\
\hline & \multicolumn{5}{|c|}{ LSD for BxC = 0.667 } \\
\hline Mean for SS & $25.12 \mathrm{a}$ & $20.85 \mathrm{~b}$ & $8.59 \mathrm{c}$ & $5.03 \mathrm{~d}$ & \\
\hline
\end{tabular}

Note: Homogeneous groups of tested variables are indicated by the same lowercase letters. 
confirmed by the data in Table 5 . The contents of this metal determined in Fr. 2 in SS3 were significantly (2-3 times) lower than its amounts in the same fraction of SS1 and SS2 (Table 5).

Regardless of the above, the literature data indicate another potential nickel distribution between the SS fractions. For example, Braga et al. (2017), Łukowski (2017) and Wojciula et al. (2021) specified the greatest amounts of this metal in oxidizable complexes and the lowest in exchangeable, water and acid soluble ones. On the other hand, Karwowska and Dąbrowska (2017) determined a small share of $\mathrm{Ni}$ in the most mobile complexes (Fr. 1 and 2) with a simultaneously dominant share in fraction 4 , i.e. residual bonds. The predominant content of $\mathrm{Ni}$ in the residual fraction was also recorded in the analyzed SS4. It could be linked to the fermentation of SS as its stabilizing process during waste management carried out at the WWTPs. In anaerobic digestion, $\mathrm{Fe}$ and $\mathrm{Ni}$ act as the cofactors of hydrogenases, participating in the acidogenic and methanogenic hydrogenotropic stages of $\mathrm{CH}_{4}$ production (Braga et al. 2017). It cannot be ruled out that in the case of SS4, Ni was not fully used during the fermentation process entering into very stable complexes representing e.g. the non-silicate, residual fraction.

The Ni amounts in individual fractions in the years of the study varied, which was least marked in the case of Fr. 1. In the SS samples from 2019, the Ni level was lower by 41 and $31 \%$ in reducible and oxidizable bonds, respectively, while the metal content in the residual fraction increased 2.0 times (Table 6). Taking into account the average for the years of the study, the amounts of $\mathrm{Ni}$ in fractions for individual
SS, significant changes were observed only for SS1 and SS2, where the metal level decreased by $39 \%$ and increased by $28 \%$, respectively, in the samples from 2017 (Table 6). Spanos et al. (2016), when analyzing quantitative changes of metals in SS, also observed various trends expressed in both higher and lower amounts of individual metals in the years of the study.

\section{Risk assessment of metals in sewage sludge}

The RAC values differed between the metals, SS and the years of the study (Table 7). Generally, the RAC values for the tested SS and the metals increased in the years of the study. Thus, the RAC values for Mn ranged from 34.80 to $43.23 \%$, indicating a high risk indicating a considerable hazard to the environment. In the case of $\mathrm{Ni}$ for SS1 and SS2 in all the years of the study, the values indicating a high risk were also determined (from 33.26 to $46.89 \%$ ). On the other hand, the RAC values for Ni in SS3 and SS4 were smaller (15.71$29.78 \%$ ), which indicates a medium risk and a relative hazard to the environment. The RAC values for $\mathrm{Mn}$ and Ni comparable to those presented in this study were given by Zhang et al. (2017). In turn, Tytla (2019) indicated similar values of RAC and considerably lower ICF values for $\mathrm{Ni}$. In the presented study, the calculated ICF values were higher for Mn and regardless of the SS increased in the years of the study. The values of ICF calculated for Mn for SS1 and SS2 (19.04-56.92) were higher than for SS3 and SS4 (15.33-26.17). An opposite trend for these changes was observed for $\mathrm{Ni}$, because the calculated ICF values decreased

Table 6. Mean nickel contents for fractions and sewage sludge depending on the years of the study $\left(\mathrm{mg} \cdot \mathrm{kg}^{-1}\right)$

\begin{tabular}{|c|c|c|c|c|}
\hline \multirow{2}{*}{ Year of study } & \multicolumn{4}{|c|}{ Fractions } \\
\hline & 1 & 2 & 3 & 4 \\
\hline 2017 & 20.38 & 25.15 & 11.18 & 4.45 \\
\hline 2018 & 21.68 & 22.78 & 12.51 & 7.11 \\
\hline 2019 & 21.98 & 14.79 & 7.72 & 9.07 \\
\hline \multirow[t]{3}{*}{ Mean for the years } & 21.35 & 20.91 & 10.47 & 6.88 \\
\hline & \multicolumn{4}{|c|}{ Sewage sludge } \\
\hline & SS1 & SS2 & SS3 & SS4 \\
\hline 2017 & 30.46 & 17.47 & 8.30 & 4.94 \\
\hline 2018 & 26.38 & 22.75 & 9.21 & 5.73 \\
\hline 2019 & 18.51 & 22.33 & 8.27 & 4.44 \\
\hline \multirow[t]{2}{*}{ Mean for the years } & 25.12 & 20.85 & 8.59 & 5.04 \\
\hline & \multicolumn{4}{|c|}{ LSD $=0.525$} \\
\hline
\end{tabular}


Table 7. Bioavailability indices, risk assessment codes and individual contamination factors assessed for Mn and $\mathrm{Ni}$ in sewage sludge in relation to the years of the study

\begin{tabular}{|c|c|c|c|c|c|c|c|c|c|}
\hline \multirow{2}{*}{ Year of study } & \multicolumn{2}{|c|}{ SS1 } & \multicolumn{2}{c|}{ SS2 } & \multicolumn{2}{c|}{ SS3 } & \multicolumn{2}{c|}{ SS4 } \\
\cline { 2 - 10 } & $\mathrm{Mn}$ & $\mathrm{Ni}$ & $\mathrm{Mn}$ & $\mathrm{Ni}$ & $\mathrm{Mn}$ & $\mathrm{Ni}$ & $\mathrm{Mn}$ & $\mathrm{Ni}$ \\
\hline & \multicolumn{7}{|c|}{ Risk assessment code (RAC) (\%) } \\
\hline 2017 & 40.76 & 33.26 & 35.68 & 37.88 & 34.56 & 26.94 & 38.21 & 28.37 \\
\hline 2018 & 41.35 & 37.34 & 39.43 & 35.97 & 36.84 & 29.76 & 35.80 & 15.71 \\
\hline 2019 & 34.80 & 46.89 & 39.50 & 44.40 & 42.14 & 30.78 & 43.23 & 18.80 \\
\hline \multicolumn{7}{|c|}{ Individual Contamination Factor (ICF) } \\
\hline 2017 & 21.17 & 17.37 & 26.07 & 12.70 & 15.33 & 9.63 & 18.91 & 5.71 \\
\hline 2018 & 19.04 & 14.74 & 22.92 & 16.03 & 25.68 & 3.93 & 24.07 & 1.58 \\
\hline 2019 & 41.11 & 5.84 & 56.92 & 8.42 & 23.20 & 3.08 & 26.17 & 1.26 \\
\hline
\end{tabular}

for all the SS in the years of the study. The nickel ICF values obtained for SS1 and SS2 (5.84-17.34) were higher compared to SS3 and SS4 (1.26-9.63) (Table 7).

\section{CONCLUSIONS}

It was found that $\mathrm{Mn}$ and $\mathrm{Ni}$, while maintaining their biogeochemical individualism, showed significant similarities, which to some extent was related to their belonging to the group of oxyphinic elements. The amounts of both metals were dominant in readily and relatively readily soluble SS combinations, which was confirmed by the values of the used indices such as the risk assessment code (RAC) and individual contamination factor (ICF). This should be interpreted on two levels. Considering the soil application of SS, a large and rapidly activated pool of micronutrients such as Mn and Ni may be a beneficial and valuable source of nutrients for plants. However, it is also necessary to take into account and consider certain dangers related to the possible accumulation of these elements in soils.

The conducted research showed a probable relationship between the quality of wastewater treatment in terms of removing $\mathrm{Mn}$ and $\mathrm{Ni}$ and their presence in sewage sludge. The decreasing amount of the metals in sewage sludge may result from a lower efficiency of wastewater treatment or an improvement in the purity and quality of drinking water distributed through the water supply system, as well as an improved quality of the water itself, especially in the case of manganese.

\section{REFERENCES}

1. Alvarenga P., Mourinha C., Farto M., Santos T., Palma P., Sengo J., Morais M-Ch., Cunha-Queda C. 2015. Sewage sludge, compost and other representative organic wastes as agricultural soil amendments: Benefits vesus limiting factors. Waste Management 40, 44-52.

2. Braga A.F.M., Zaiat M., Silva G.H.R., Fermoso F.G. 2017. Metal fractionation in sludge from sewage UASB treatment. Journal of Environment Management 193, 98-107.

3. CSO. Central Statistical Office. Environment Protection. 2019. https://stat.gov.pl/obszary-tematyczne/srodowisko-energia/srodowisko/ochronasrodowiska-2019,1,20.html (access 22nd of March 2021).

4. Collivignarelli M.C., Abbà A., Frattarola A., Miino M.C., Padovani S. 2019. Legislation for the Reuse of Biosolids on Agricultural Land in Europe: Overview. Sustainability 11, 6015, doi:10.3390/ su11216015.

5. Contin M., Malev O., Izosimova A., De Nobili M. 2015. Flocculation of sewage sludge with $\mathrm{FeCl} 3$ modifies the bioavailability of potentially toxic elements when added to different soils. Ecological Engineering 81, 278-288.

6. Directive $86 / 278 /$ EEC on the protection of the environment, and in particular of the soil, when sewage sludge is used in agriculture. https://eur-lex.europa.eu/legal-content/EN/ ALL/?uri=CELEX\%3A31986L0278 (access 22nd of March 2021).

7. Directive 1991/271/EEC. https:// eur-lex.europa.eu/legal-content/EN/ $\mathrm{TXT} /$ ?uri=celex\%3A31991L0271 (access 22nd of March 2021).

8. Directive 1999/31/ EC (Landfill Directive). https:// eur-lex.europa.eu/legal-content/en/ALL/?uri=CEL EX\%3A31999L0031(access 22nd of March 2021).

9. Duan B., Zhang W., Zheng H., Wu C., Zhang 
Q., Bu Y. 2018. Disposal distribution of sewage sludge from municipal wastewater treatment plants (WWTPs) and assessment of the ecological risk of heavy metals for its land use in Sanxi, China. International Journal of Environmental Research and Public Health 14, 823.

10. Eurostat. https://ec.europa.eu/eurostat (access 22nd of March 2021).

11. Genchi G., Carocci A., Lauria G., Sinicropi M.S., Catalano A. 2020. Nickel: Human health and environmental toxicology. International Journal of Environmental Research and Public Health 17, 679, doi:10.3390/ijerph17030679.

12. Górecki T., Jakubus M., Krzyśko M., Wołyński W. 2020. Application of distance covariance in selection of nutrients during dynamic process of sewage sludge conditioning with Bio-preparation. Waste Biomass and Valorisation 11 (8), 4157-4166.

13. ISO 1995. ISO 11466: Soil quality - Extraction of trace elements soluble in aqua regia. International Organization for Standardization, Genève, Switzerland.

14. Jakubus M. 2020. Changes in lead and chromium contents in sewage sludge evaluated using both single extractants and sequential method. Environmental Pollutants and Bioavailability 32 (1), 87-99.

15. Jakubus M., Bakinowska E. 2018. Visualization of long-time quantitative changes of microelements in soils amended with sewage sludge compost evaluated with two extraction solutions. Communication in Soil Science and Plant Analysis 49, 11, 1355-1369.

16. Jakubus M., Bakinowska E., Tobiasova E. 2021. Valorisation of sewage sludge humic compounds in the aspect of its application in natural environment. Environment Protection Engineering 47, (1), 67-83.

17. Kabata-Pendias A, Pendias H. Biogeochemistry of trace elements. PWN. Warszawa (1999) (in Polish).

18. Karwowska B., Dąbrowska L. 2017. Bioavailability of heavy metals in the municipal sewage sludge. Ecological Chemistry and Engineering S, 24(1), 75-86.

19. Kim R-Y., Yoon J-K., Kim T-S., Yang J.E., Owens G., Kim, K-R. 2015. Bioavaialability of heavy metals in soils: definitions and practical implementation - a critical review. Environmental Geochemistry and Health 37, 1041-1061.

20. Łukowski A. 2017. Fractionation of selected heavy metals $(\mathrm{Zn}, \mathrm{Ni}, \mathrm{Cu})$ in municipal sewage sludges from Podlasie Province. Ecological Engineering 18 (3), 133-139.

21. Mossop K.F., Davidson Ch.M. 2003. Comparison of original and modified BCR sequential extraction procedures for the fractionation of copper, iron, lead, manganese and zinc in soils and sediments. Analityca Chemica Acta 478, 1, 111-118.
22. Pöykio R., Watkins G., Dath O. 2019. Characterisation of municipal sewage sludge as a soil improver and a fertilizer product. Ecological Chemistry and Engineering S 26 (3), 547-557.

23. Regulation of Ministry of Environment on sewage sludge. Journal of Laws of 2015, item 257.

24. Röllin H.B., Nogueira C.M.C.A. 2011. Manganese. Environmental pollution and Health Effects. In: JO Nriagu (Ed) Encyclopedia of Environmental Health (Burlington, Elsievier), pp. 617-629.

25. Sanchez C.H., Gutierrez,A., Galindo J.M., Gonzalez-Weller D., Rubio C., Revert C., Burgos A., Hardisson A. 2017. Heavy metal content in sewage sludge: a management strategy for an Ocean Island. Revista de Salud Ambiental, 17(1), 3-9.

26. Sharma B., Sarkar A., Singh P., Singh RP. 2017. Agricultural utilisation of biosolids: A review on potential effects on soil and plant grown. Waste Management 64, 117-132.

27. Spanos T., Ene A., Stylian Patronidou Ch., Xatzixristou Ch. 2016. Temporal variability of sewage sludge heavy metal content from Greek wastewater treatment plants. Ecological Chemistry and Engineering S 23 (2), 271-283.

28. Tytla M. 2019. Assessment of heavy metal pollution and potential ecological risk in sewage sludge from municipal wastewater treatment plant located in the most industrialized region in Poland-Case Study. International Journal of Environmental Research and Public Health 16, 2430, doi:10.3390/ ijerph16132430.

29. WHO Guidelines for drinking-water quality. (2017) https://apps.who.int/iris/bitstream/hand le/10665/254637/9789241549950-eng.pdf;jsession $\mathrm{id}=4 \mathrm{C} 18401 \mathrm{~A} 2 \mathrm{AB} 53 \mathrm{E} 4706 \mathrm{~A} 5 \mathrm{~B} 88 \mathrm{~B} 8 \mathrm{D} 27 \mathrm{D} 411$ ?se quence $=1$ (access 22nd of March 2021).

30. Wojciula A., Boruszko D., Pajewska G. 2021. Analysis of heavy metal fraction content in sewage sludge from selected wastewater treatment plants. Journal of Ecological Engineering 22(4), 98-105.

31. Yang T., Huang H., Lai F. 2017. Pollution hazards of heavy metals in sewage sludge from four wastewater treatment plants in Nanchang, China. Transactions of Nonferrous Metals Society of China 27, 2249-2259.

32. Zhang X., Wang X., Wang D. 2020. Immobilization of Heavy Metals in Sewage Sludge during Land Application Process in China: A Review. Sustainability 9, 2017, doi:10.3390/su9112020.

33. Zhang J., Tian Y., Zhang J., Li N., Kong L., Yu M., Zuo W. 2017. Distribution and risk assessment of heavy metals in sewage sludge after ozonation. Environmental Science and Pollution Research 24, 5118-5125. 